\title{
Application of a hygroscopicity tandem differential mobility analyzer for characterizing PM emissions in exhaust plumes from an aircraft engine burning conventional and alternative fuels
}

Max B. Trueblood et al.

Correspondence to: Max B. Trueblood (trueblud@mst.edu)

The copyright of individual parts of the supplement might differ from the CC BY 4.0 License. 


\section{Supplemental Information}

$\Phi_{\mathrm{S}}$ can be related to the square root of the molality $(\psi)$ by a $6^{\text {th }}$ order polynomial function. Figures S1 and S2 below show two examples of this. Fig. S1 shows the osmotic coefficient of $\left(\mathrm{NH}_{4}\right)_{2} \mathrm{SO}_{4}$ as provided by Robinson and Stokes as symbols. The solid lines in the plot are linear extrapolations of that data. The line on the right is a linear extrapolation from the last 5 data points. The straight line on the left is simply a line joining the last point and zero. The sixth order polynomial is an excellent fit to the data.

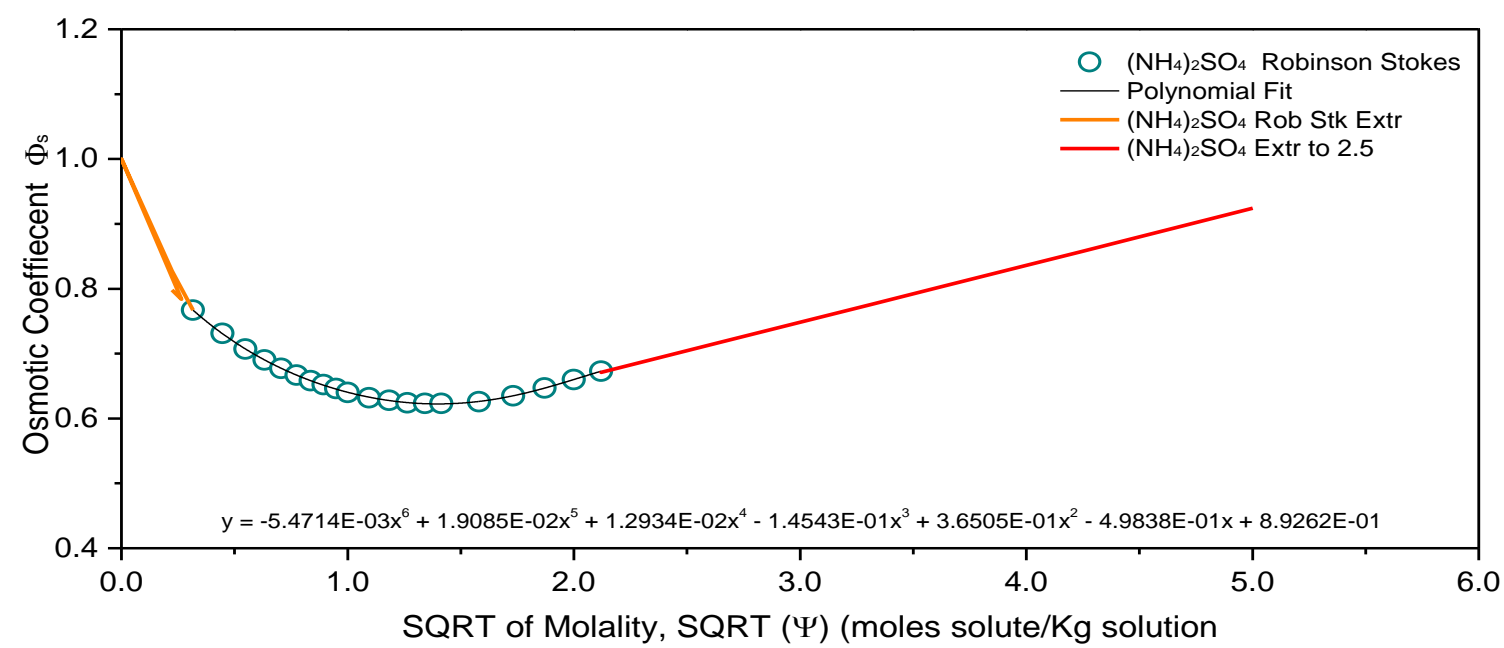

Fig. S1. The osmotic coefficient of $\left(\mathrm{NH}_{4}\right)_{2} \mathrm{SO}_{4}$ as provided by Robinson and Stokes is shown as symbols and the extrapolations are shown as straight lines. Note that the osmotic coefficient is considerably different from unity.

Fig $\mathrm{S} 2$ is a plot of the osmotic coefficient of $\mathrm{NaCl}$ as a function of the square root of the molality as provided by Hammer and $\mathrm{Wu}$. Note that again the literature provided values do not cover the desired range. Thus the range was extended by a linear extrapolation of the last five data points. 


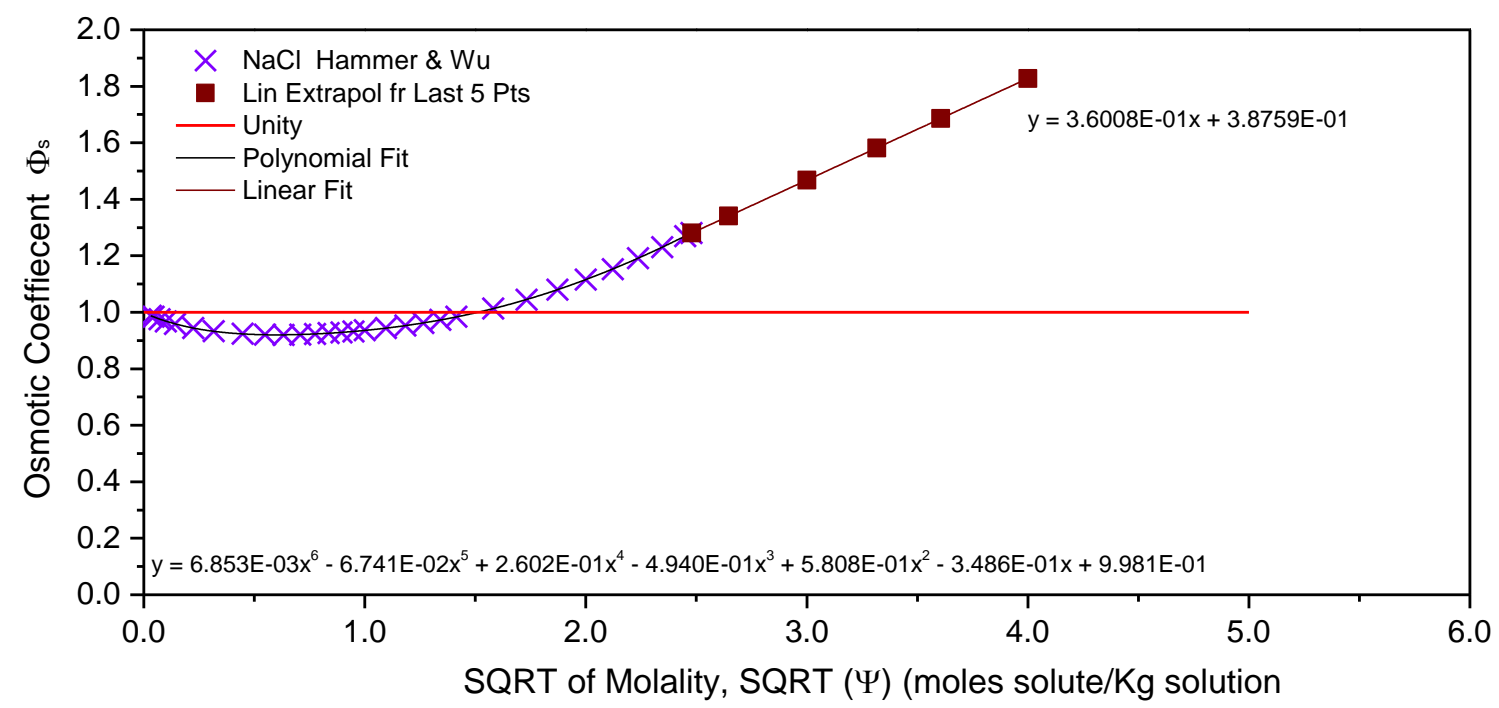

Fig. S2. The osmotic coefficient of $\mathrm{NaCl}$ as provided by Hammer and $\mathrm{Wu}$ is shown as symbols and the extrapolation is shown as a straight line. Note that the osmotic coefficient is considerably different from unity.

There is a feature within the LabVIEW program that compares the calculated value of the molality $(\psi)$ to the range over which tabulated data from the literature exists. If the calculated value of the molality is within that range, then the program uses the sixth order polynomial to compute the osmotic coefficient. If the calculated value of the molality is outside of that, then the osmotic coefficient is computed from the linear extrapolation. Also, the dependency of $\Phi_{\mathrm{s}}$ on $\mathrm{X}_{\mathrm{d}}$ and $\mathrm{X}_{\mathrm{w}}$ diameters are taken into account.

In this paper we present the performance evaluation of the MST H-TDMA when sampling challenge aerosols of $\mathrm{NaCl}, \mathrm{KI}, \mathrm{KCl}$ and $\left(\mathrm{NH}_{4}\right)_{2} \mathrm{SO}_{4}$. For all of these salts and the diameters chosen, the calculated molality is such that the osmotic coefficient can be taken from the published data and need not be taken from extrapolated values.

However, for the data on the hybrid particles sampled at AAFEX II, about half of the data points are such that the calculated molality is larger than what there is published data for, and therefore the LabVIEW program used the extrapolated values for the osmotic coefficient. Table S1 lists the properties of the chemicals used as challenge aerosols.

Table S1. Chemical Properties

\begin{tabular}{|l|c|c|c|}
\hline \multicolumn{1}{|c|}{ Chemical } & $\begin{array}{c}\text { Molecular Weight } \\
\mathbf{g} / \mathbf{m o l e}\end{array}$ & $\begin{array}{c}\text { Density } \\
\mathbf{g} / \mathbf{c m}^{\mathbf{3}}\end{array}$ & Number of Ions \\
\hline Ammonium Sulfate, $\left(\mathrm{NH}_{4}\right)_{2} \mathrm{SO}_{4}$ & 132.14 & 1.77 & 3 \\
\hline Sodium Chloride, $\mathrm{NaCl}$ & 58.44 & 2.165 & 2 \\
\hline Potasium Chloride, $\mathrm{KCl}$ & 74.55 & 1.984 & 2 \\
\hline Potasium Iodide, $\mathrm{KI}$ & 166.003 & 3.123 & 2 \\
\hline
\end{tabular}


Table S2. Formulas for computing the Osmotic Coefficients

\begin{tabular}{|c|c|}
\hline Chemical & Formula for Osmotic Coefficient, where X = SQRT $(\Psi)$ \\
\hline$\left(\mathrm{NH}_{4}\right)_{2} \mathrm{SO}_{4}$ & $\begin{array}{l}\Phi_{\mathrm{S}}=-5.4714 \mathrm{E}-03 \mathrm{x}^{6}+1.9085 \mathrm{E}-02 \mathrm{x}^{5}+1.2934 \mathrm{E}-02 \mathrm{x}^{4}-1.4543 \mathrm{E}-01 \mathrm{x}^{3}+3.6505 \mathrm{E}-01 \mathrm{x}^{2}-4.9838 \mathrm{E}-01 \mathrm{x} \\
+8.9262 \mathrm{E}-01\end{array}$ \\
\hline $\mathrm{NaCl}$ & $\begin{array}{l}\Phi s=6.85306 \mathrm{E}-03 \mathrm{x}^{6}-6.74096 \mathrm{E}-02 \mathrm{x}^{5}+2.60152 \mathrm{E}-01 \mathrm{x}^{4}-4.94046 \mathrm{E}-01 \mathrm{x}^{3}+5.80850 \mathrm{E}-01 \mathrm{x}^{2}- \\
3.48589 \mathrm{E}-01 \mathrm{x}+9.98115 \mathrm{E}-01\end{array}$ \\
\hline $\mathrm{KCl}$ & $\begin{array}{l}\Phi \mathrm{S}=9.4090 \mathrm{E}-03 \mathrm{x}^{6}-8.1718 \mathrm{E}-02 \mathrm{x}^{5}+2.8811 \mathrm{E}-01 \mathrm{x}^{4}-5.2561 \mathrm{E}-01 \mathrm{x}^{3}+5.7796 \mathrm{E}-01 \mathrm{x}^{2}-3.6900 \mathrm{E}-01 \mathrm{x}+ \\
9.9914 \mathrm{E}-01\end{array}$ \\
\hline KI & $\begin{array}{l}\Phi \mathrm{s}=1.4020 \mathrm{E}-02 \mathrm{x}^{6}-1.0864 \mathrm{E}-01 \mathrm{x}^{5}+3.4581 \mathrm{E}-01 \mathrm{x}^{4}-5.9377 \mathrm{E}-01 \mathrm{x}^{3}+6.3594 \mathrm{E}-01 \mathrm{x}^{2}-3.6434 \mathrm{E}-01 \mathrm{x}+ \\
9.9880 \mathrm{E}-01\end{array}$ \\
\hline
\end{tabular}

